\title{
3D MODELS OF THE QH31, QH32 AND QH33 TOMBS IN QUBBET EL HAWA (ASWAN, EGYPT)
}

\author{
A. T. Mozas-Calvache ${ }^{1, *}$, J. L. Pérez-García ${ }^{1}$, J. M. Gómez-López ${ }^{1}$, J.L. Martínez-de Dios ${ }^{2}$, A. Jiménez-Serrano ${ }^{2}$ \\ ${ }^{1}$ Dept. Ingeniería Cartográfica, Geodésica y Fotogrametría, University of Jaén, 23071 Jaén, Spain - (antmozas, jlperez, \\ jglopez)@ujaen.es \\ ${ }^{2}$ Dept. Antropología, Geografía e Historia, University of Jaén, 23071 Jaén, Spain - jlmd0001@ red.ujaen.es, ajiserra@ujaen.es
}

\section{Commission II, WG II/8}

KEY WORDS: Close Range Photogrammetry, TLS, 3D model, Egyptian tombs

\begin{abstract}
:
This paper describes the methodology employed to obtain 3D models of three funerary complexes (QH31, QH32 and QH33) of the Necropolis of Qubbet el Hawa (Aswan, Egypt) and the main results obtained. These rock-cut tombs are adjacent structures defined by complex geometries such as chambers, corridors and vertical shafts. The main goal of this study was to discover the spatial relationships between them and obtain a complete 3D model. In addition, some models with realistic textures of the burial chambers were demanded in order to analyse archaeological, architectural and geological aspects. The methodology was based on the use of Terrestrial Laser Scanning and Close Range Photogrammetry. In general, both techniques were developed in parallel for each tomb. Some elements presented difficulties because of their reduced dimensions, the presence of vertical falls, some objects stored in the tombs that generated occlusions of some walls, coincidence of other workers, poor illumination conditions, etc. The results included three complete 3D models obtained without texture and some parts of interest obtained with real textures. All models were merged into a global 3D model. The information extracted from this product has helped architects and archaeologists to contrast their premises about the spatial behaviour of the tombs. The results have also allowed the obtaining of the first 3D documentation of these tombs under the same reference system, allowing them to be studied completely. This information is very important for documentation purposes but also to understand the spatial behaviour of these structures and the excavation processes developed by ancient Egyptians 4000 years ago.
\end{abstract}

\section{INTRODUCTION}

The 3D documentation of heritage has undergone a great development during the last decades mainly based on the use of new sensors and platforms and new processing applications. We can highlight the evolution of photogrammetry and Light Detection and Ranging (LiDAR) as examples of techniques that have led this development. In the case of photogrammetry this evolution has supposed, as examples, the general use of lowcost non-metric cameras (Ogleby et al., 1999; Celikoyan, 2003; Cardenal et al., 2004; Chandler et al., 2005; Covas et al., 2015; Fiorillo et al., 2016; Barazzetti, 2017a and 2017b) and new platforms to lift these cameras, such as Remotely Piloted Aircraft Systems (RPAS) (Colomina, Molina, 2014; Nex, Remondino, 2014; Campana, 2017), or masts (Georgopoulos, 1999; Mozas-Calvache et al., 2012; Martínez et al. 2013; Ortiz et al., 2013; Blockley, Morandi, 2015; Martínez et al., 2015; Pérez et al., 2019). In the case of LiDAR, the development of Terrestrial Laser Scanning has allowed the acquisition of large point clouds of monuments and artefacts, achieving great values of efficiency and accuracy (Brutto, Meli, 2012; Green et al., 2014). In addition to the development of these methods, we also must consider the great evolution of computing capacities and algorithms. In this sense, we highlight the development and democratization (Westoby et al., 2012) of several applications based on algorithms that have allowed access to photogrammetry to other professionals not specialized in classical photogrammetry. Algorithms such as Structure from Motion (SfM) (Ullman, 1979; Koenderink, Van Doorn, 1991; Lowe, 2004; Szeliski, 2011) and the dense MultiView Stereo
3D reconstruction (MVS) (Scharstein, Szeliski, 2002; Seitz et al., 2006; Szeliski, 2011; Furukawa, Hernández, 2015) are included in several photogrammetric applications (Agisoft Metashape, Colmap, VisualSFM, Bentley ContextCapture, Sure) (Brutto, Meli, 2012; Rothermel et al., 2012; McCarthy, 2014).

Regarding the application of these techniques to indoor studies several examples have been described in the literature where techniques based on short distances (Close Range Photogrammetry, TLS, etc.) were applied. As examples, there are applications in caves (Lerma et al., 2010), rock-cut tombs (Nabil et al., 2013) and historical buildings (Guarnieri et al., 2006). In general, the main issue in this type of studies is related to the presence of reduced and narrow spaces. In this sense, several studies have shown smart solutions based on the use of fisheye lenses (Covas et al., 2015; Perfetti et al., 2017) or low-weight cameras located on masts (Fiorillo et al., 2016; José Luis et al., 2019). In the case of studies of tombs, several applications have been developed using both photogrammetry (Angelini et al., 2016; José Luis et al., 2019) and TLS (Ahmon, 2004; Fernández-Palacios et al., 2013; Nabil et al., 2013; Lima, Vergauwen, 2018; Echeverria et al., 2019).

Considering the current possibilities of the geomatic techniques, in this study we describe the method carried out and the results obtained after their application to several funerary complexes (QH31, QH32 and QH33) in the Necropolis of Qubbet el Hawa (Aswan, Egypt). The complex structures of these rock-cut tombs, composed of several chambers, corridors, vertical shafts, etc., jointly with the presence of narrow and reduced spaces, poor illumination conditions and the presence of other works, 
supposed an important challenge when using these techniques, despite their current level of development. The main goal was to obtain a complete 3D model of these non-connected structures referred to the same coordinate system as the exterior. In addition, some models with realistic textures of the burial chambers were needed in order to analyse archaeological, architectural and geological aspects.

\subsection{Description of the QH31, QH32 and QH33 funerary complexes}

The Necropolis of Qubbet el Hawa is located in a medium-high hill situated on the west bank of the Nile River (Figure 1a). The geological and topographic characteristics of this site allowed the excavation of a large quantity of funerary structures in the rock in ancient Egypt. The matter that concerns this study is related to three funerary complexes $(\mathrm{QH} 31, \mathrm{QH} 32$ and QH33) located in the middle of the hill where the necropolis is distributed (Figure 1b and Figure 1c). These rock-cut tombs are adjacent structures with a separation between their entrances of about 20m (Figure 1d). This closeness justifies the analysis of the interior structures together in order to determine their behaviour and the construction processes developed in antiquity.

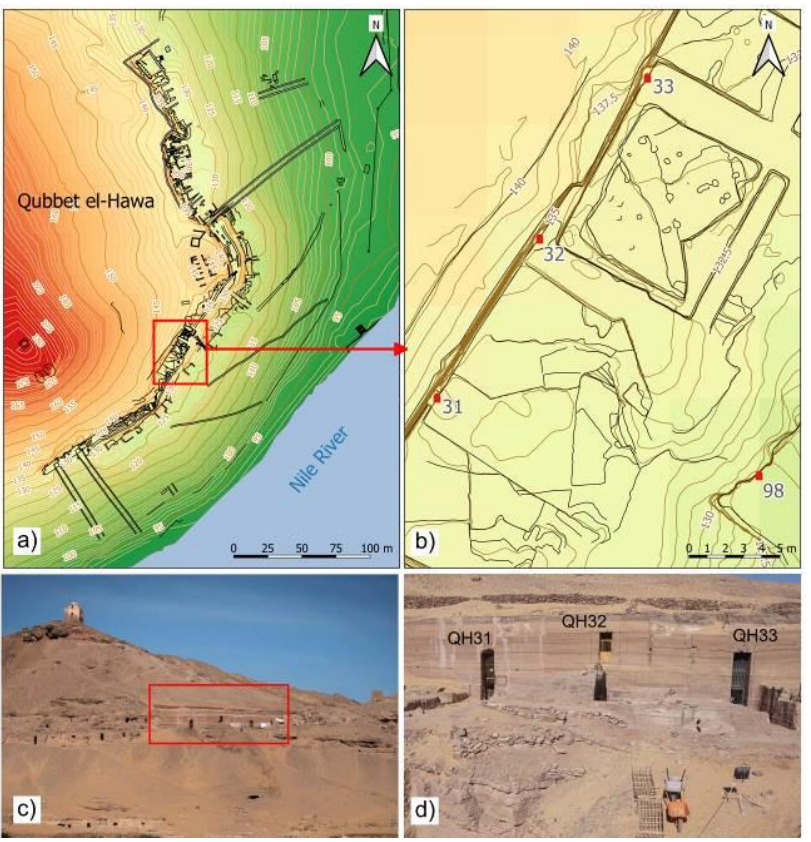

Figure 1. Study zone: a) map of the Necropolis of Qubbet el Hawa; b) location of the tombs; c) general view; d) detailed view of the entrance of the tombs.

Focusing on the interior parts of the tombs (Figure 2), the dimensions are about $32 \mathrm{~m}, 22 \mathrm{~m}$ and $23 \mathrm{~m}$ of length, $23 \mathrm{~m}, 13$ $\mathrm{m}$ and $10 \mathrm{~m}$ of width, and $18 \mathrm{~m}, 9 \mathrm{~m}$ and $18 \mathrm{~m}$ of height respectively. We must highlight that the complex structures of the tombs are spatially well organized without any interference between them, despite their closeness. The structure of these tombs is composed of two distinct areas: the funeral chapel, which was accessible, and the burial area, which was inaccessible (Martínez-Hermoso et al., 2015). Despite the particular features, all the tombs contain similarities and common spaces:

1. An initial hypostyle hall composed of several pillars (Figure 2a).
2. A corridor that connects to the funerary chapel $(\mathrm{QH} 31$ and QH32).

3. A funerary chapel (QH31 and QH32) (Figure 2b) (accessible only to the funerary priests and the closest relatives).

4. A sanctuary located at the back wall of this chapel (QH31 and QH32) (Figure 2b) or at the back wall of the hypostyle hall (QH33).

5. A corridor that connects these spaces to the vertical shaft (Figure 2c and Figure 2d).

6. A vertical shaft (up to $13 \mathrm{~m}$ in the case of the QH33 tomb) (Figure 2e).

7. The main burial chamber at the bottom of this shaft (Figure 2f).

8. Secondary burial chambers are located in previous spaces such as hypostyle halls, corridors, etc.
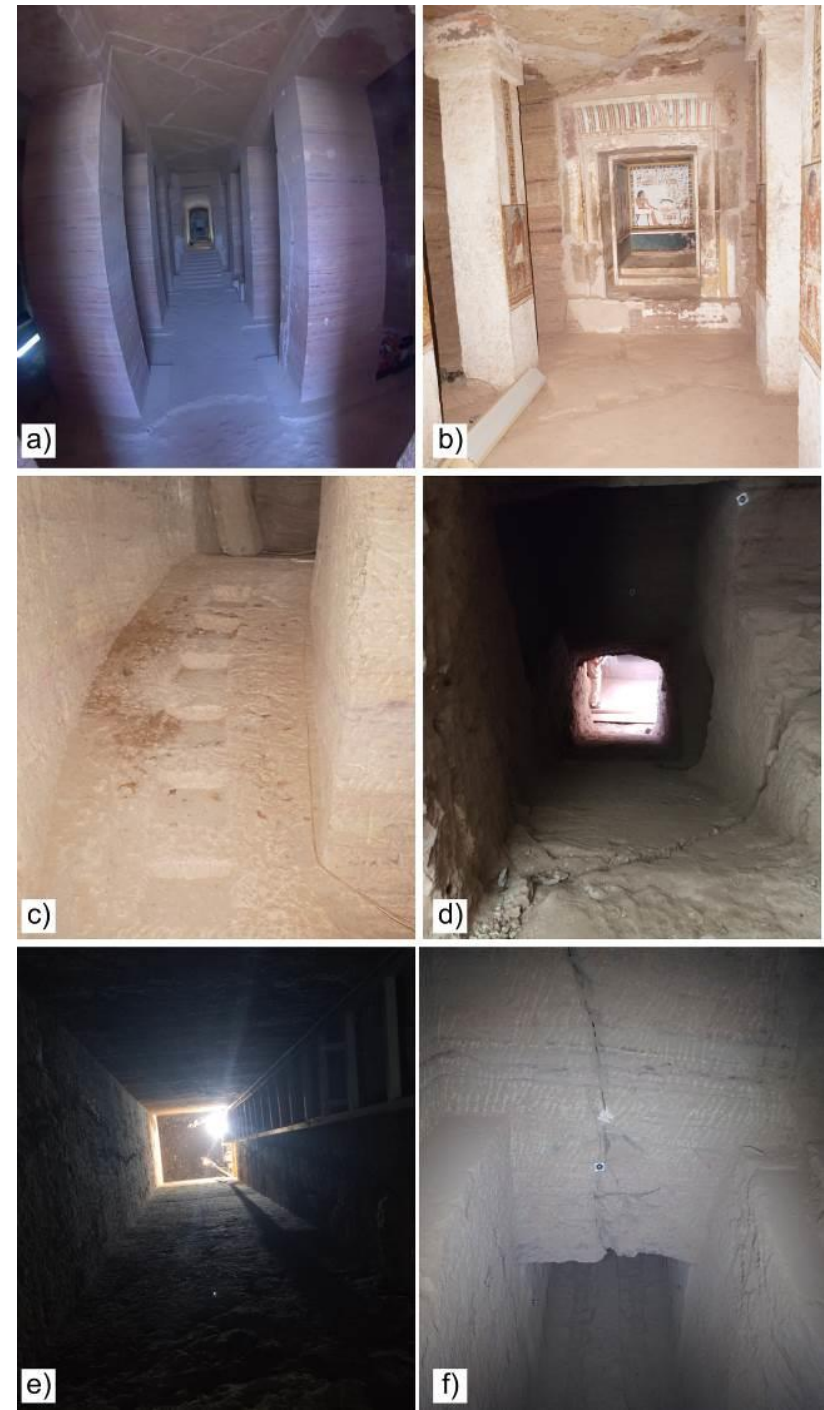

Figure 2. Examples of interior spaces: a) QH31 hypostyle hall;

b) QH31 chapel of offerings and Sanctuary; c) QH32 corridor;

d) QH31 corridor; e) QH33 vertical shaft; f) QH31 burial chamber.

A priori, the complex structure of these tombs causes several difficulties in carrying out a photogrammetric and/or TLS study. As examples, the hypostyle halls present large dimensions but there are several pillars inside that complicate the acquisition of data. The corridors have reduced spaces and a certain slope 
which hinders displacement and the stationing of the instruments. The vertical shafts present reduced spaces and depths of up to $13 \mathrm{~m}$. In addition, there are more difficulties caused by poor illumination conditions and security concerns. Finally, the burial chambers have reduced spaces, poor illumination conditions and the presence of dust. In addition, all spaces present occlusions caused by objects stored in the tombs that cannot be moved.

\subsection{Historical context}

Qubbet el Hawa was the necropolis of the ruling class of the southernmost province of Egypt from the second half of the $6^{\text {th }}$ Dynasty till the end of the $12^{\text {th }}$. QH31, QH32 and QH33, dated to the second half of the $12^{\text {th }}$ Dynasty (under the kings Senwosret II and Amenmehat III, 1845-1773 BC), were the last rock tombs built in this cemetery. In these funerary complexes the governors of Elephantine, their nuclear families and some prominent members of their households were buried (JiménezSerrano, Sánchez-León, 2019).

One of the main features of these tombs is the monumentality, which clearly reproduces the social position of their owners. The construction of these funerary complexes must have taken several years to build, and doubtless that explains why only the interior parts were completely finished, in contrast to the exterior courtyards which are unfinished (Jiménez-Serrano, García-González, 2017).

In some of the finished areas, concretely in the "public" spaces (hypostyle halls, corridors and funerary chapels), we must highlight the extraordinary carving and polishing work done by the artisans, who originally worked for the royal palace. These artisans were moved to Elephantine after a royal command by king Senwosret I (Habachi, 1985).

It has been possible to reconstruct a preliminary chronology of the tombs from the inscriptions and the material culture found in the course of the archaeological excavations carried out since 2008. Therefore, we have concluded that the earliest tomb of this group is QH32, which is still under excavation and might date to the reign of Senwosret II. Although the name of the owner has not been found yet, we have already suggested that it belonged to the governor Khema after the analysis of different architectonic features. QH32 was immediately followed by the construction of QH31, which is one of the finest examples of ancient Egyptian art and architecture. This tomb was constructed for Sarenput II, who lived between the reigns of Senwosret II and Senwosret III. Architectonically it is the largest and most complex of the whole of the necropolis (Martínez-Hermoso et al., 2018).

The last funerary complex, QH33, was most likely constructed for governor Heqaib-ankh at the end of the reign of Senwosret III or the earliest years of Amenemhat III. Shortly after the burial of this governor his successor, his step-brother Heqaib III died and was buried in a secondary shaft, which was rapidly constructed in the south-western corner of the hypostyle hall (Martínez-Hermoso et al., 2018).

As far as we know today, QH33 was the last tomb constructed for a governor in the hill known today as Qubbet el Hawa. Its architectonic features are unique and represent the culmination of the local funerary architecture.

\section{METHOD AND APPLICATION}

The method to be developed was selected considering the objectives, the availability of instruments and resources and the characteristics of the funerary complexes. The method implemented was based on the use of Terrestrial Laser Scanning (TLS) and Close Range Photogrammetry (CRP). In general, both techniques were developed in a parallel way in each tomb (Figure 3) although some elements presented difficulties in their acquisition because of their reduced dimensions or the presence of vertical falls (the height of the vertical shaft of the QH33 tomb is about $13 \mathrm{~m}$ ) (Figure 2e). In addition, other issues added more complexity to the field and office work such as the presence of objects stored in the tombs which generated the occlusion of some walls, the coincidence of other workers, the illumination conditions, etc. To facilitate the field work each tomb was studied independently and finally, all products were merged.

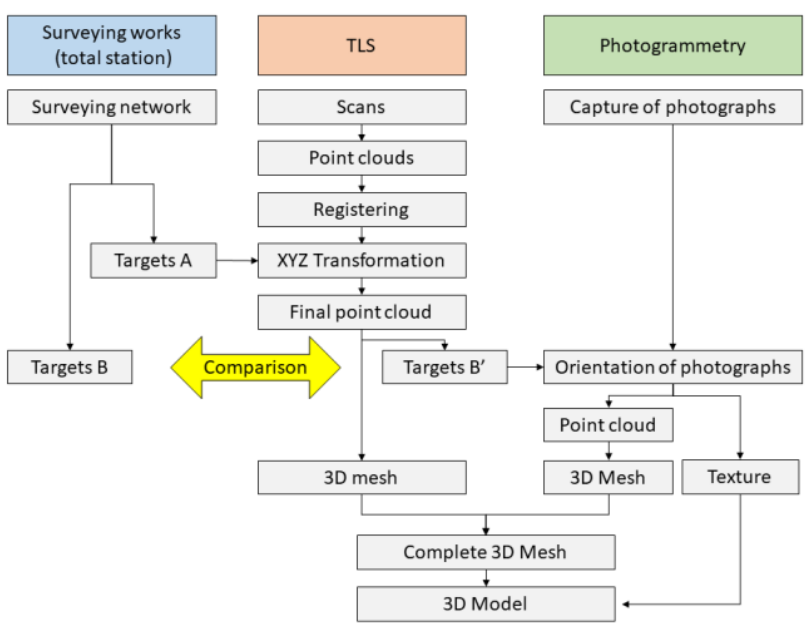

Figure 3. Methodology developed in this study.
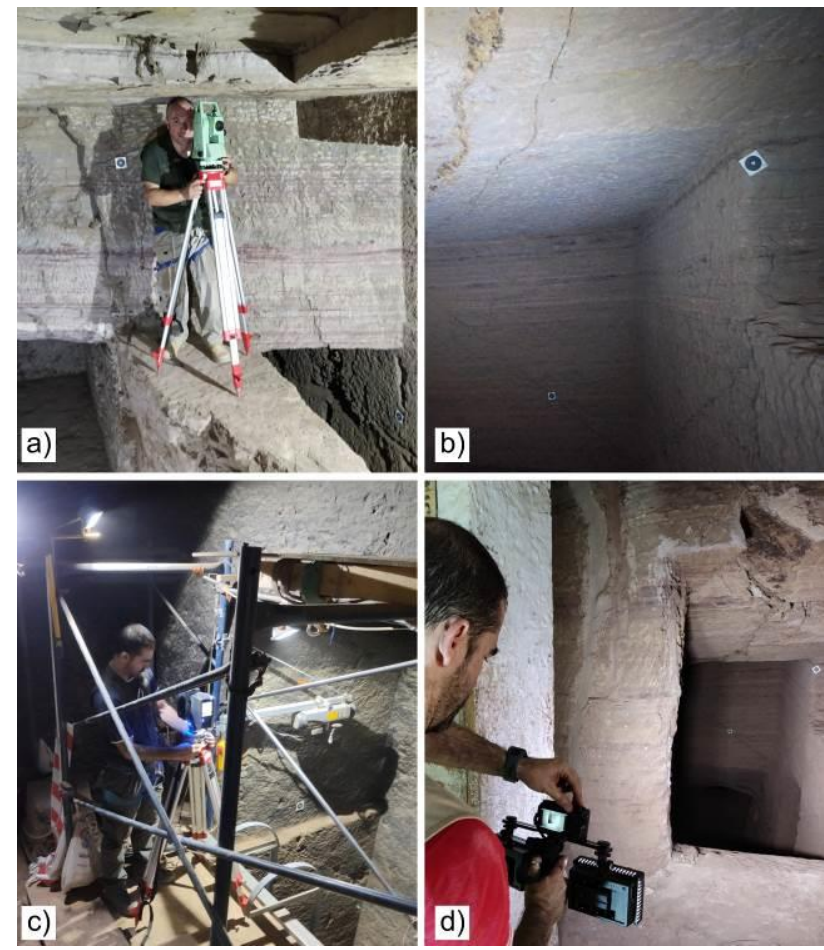

Figure 4. Examples of acquisition stages: a) surveying network using a total station; b) Detail of artificial targets; c) Scanning the QH33 vertical shaft; d) capture of photographs.

The methodology developed in this study is summarized in Figure 3. The first stage included the implementation of 
surveying networks in each tomb based on the calculation of several points using a total station (Figure 4a). These networks were referred to the exterior network of the project. The distribution of points considered the necessity of visibility between contiguous points. However, the presence of vertical shafts caused problems with the transfer of the surveying network. We used a system based on plumblines to define several points located at the bottom of the shafts, which allowed us to continue the surveying network to the final burial chambers. Once the surveying network was defined the coordinates of a set of artificial targets well-distributed on the walls were measured and estimated from these points. Some targets were used for orientation procedures for TLS (Targets A in Figure 3) and others for checking these orientations (Targets $\mathrm{B})$. The design and dimensions of the targets were selected considering a mean distance to the object (Figure 4b).

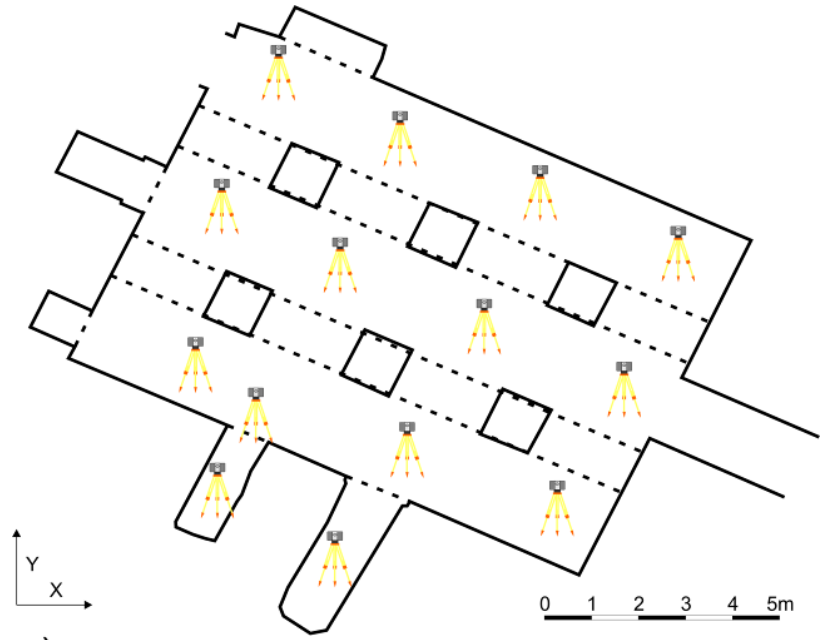

a)

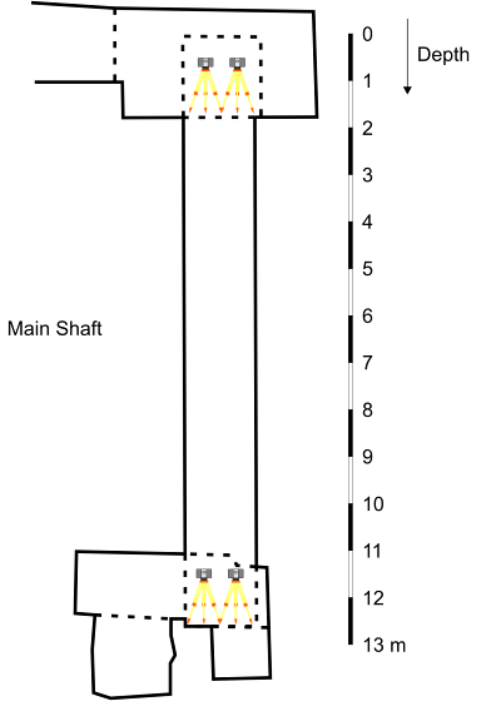

b)

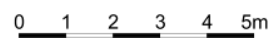

Figure 5. Distribution of scanning stations in the QH33 tomb: a) top view of the Hypostyle hall; b) side view of the main shaft.

The next stages consisted of the acquisition of TLS and photographs independently. First, we scanned the tombs using TLS (Faro Focus X130) (Figure 4c). The acquisition procedure consisted of the scanning of the object from several stations considering the necessity of a common overlapped zone between adjacent stations. This zone guarantees complete coverage of the object and the correct relative registration of the scans. This aspect is very important when merging individual point clouds obtained from several scanning stations. As an example, Figure 5 describes a summary of the distribution of scanning stations developed in the QH33 case. Considering the hypostyle hall, a scanning station was situated at every intersection generated between the pillars (Figure 5a) in order to guarantee a complete overlapped coverage. The scanning configuration consisted of the acquisition of points with density of $0.7 \mathrm{~cm}$ at $10 \mathrm{~m}$ without RGB registration in order to obtain a fast scan. This high density was selected both to guarantee the registration process and to estimate the coordinates of the targets properly. In this sense, all cloud points will filter in subsequent stages. To add difficulties to the field work other researchers and workers were studying the tombs simultaneously. Therefore, the acquisition time needed to be as fast as possible. The scanning stage was affected by several difficulties (occlusions, reduced space, presence of dust, etc.). As an example, the vertical shafts were scanned from several stations located close to the access and from the bottom of the shafts attempting to guarantee a common zone in order to register all scans relatively (Figure 5b). As result, we obtained an almost complete point cloud of each tomb that was then transformed to the global reference system using several targets (Targets A). All point clouds were edited and simplified. Finally, we obtained a 3D model of each tomb. The coordinates of additional targets (Targets B) estimated from the surveying network and from the TLS were compared in order to analyse accuracy differences between both techniques.

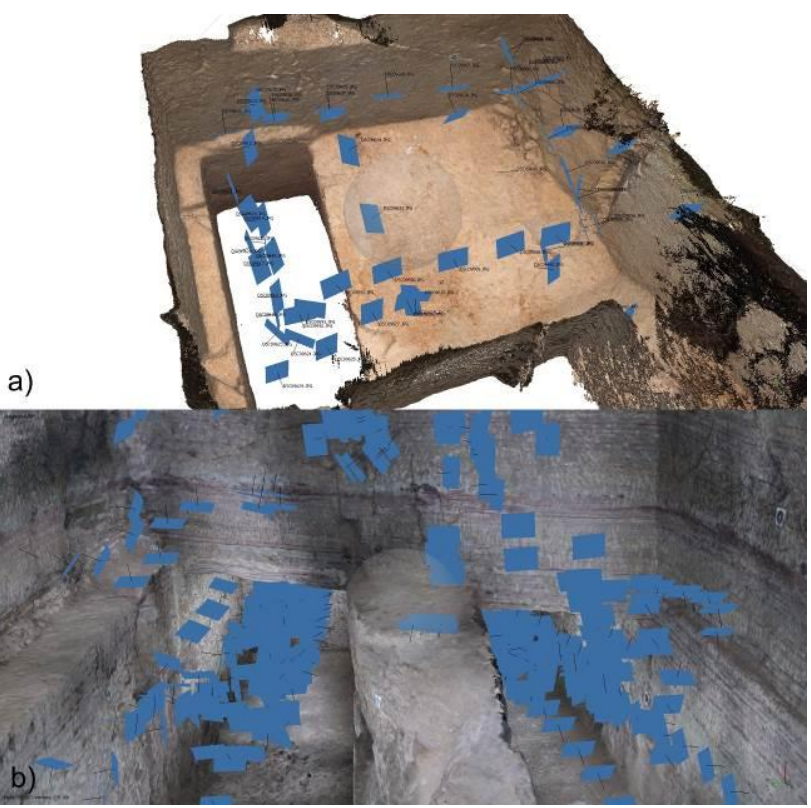

Figure 6. Distribution of photographs in: a) QH32 Intermediate chambers; b) QH33 Burial chambers.

Next we captured photographs using a non-metric conventional camera (Sony alfa 5000) (Figure 4d). The acquisition procedure considered the recommendations of the International Committee of Architectural Photogrammetry (CIPA) for architectural photogrammetric projects using non-metric cameras (known as $3 \times 3$ rules) (Waldhäusl, Ogleby, 1994; Waldhäusl et al., 2013). The highlight of the acquisition procedure is the multiple photographic all-around coverage which involves taking a ring of images all around the object and these overlapping each other by more than $50 \%$. We captured normal and convergent photographs covering all objects. Some examples of the 
distribution of photographs are shown in Figure 6. The acquisition of photographs was not possible in several parts of the tombs (e. g. in vertical shafts) because of space limitations, illumination conditions, the presence of occlusions and security concerns. After photograph acquisition all images were checked and processed. For this purpose we used the Agisoft Metashape software. More concretely, we oriented the photographs using the coordinates of several targets calculated from the TLS point cloud (Targets B') and thus obtained the 3D meshes and the textures. Finally, we obtained complementary 3D meshes from the TLS and photogrammetry and the final 3D model.

\section{RESULTS AND DISCUSSION}

The main result of this study includes three 3D models of the tombs (Figure 7a). These models were obtained without texture using TLS. In addition, some parts of the tombs were obtained with real textures using photogrammetry (Figure 8). We highlight the value of these models because of their geometric and radiometric quality. As examples, the geological stratigraphy and the chisel marks are clearly visible (view detailed views in Figure 8). The 3D models obtained using both techniques were supplementary in zones where only one model could be generated. In addition, we have compared both models in common zones in order to determine differences between them, with the results showing a low number of discrepancies (Figure 8c). As an example, the histogram represented in Figure $8 \mathrm{~d}$ shows the difference in the measured distances between the CRP model and the TLS model of the QH33 burial chamber to be lower than $2 \mathrm{~cm}$ in general. Finally, the three models were merged into a global 3D model including all tombs (Figure 7) where the spatial behaviour between them is clearly shown. In addition, a previous 3D model of the exterior (Pérez-García et al., 2018) can be included (Figure 7b).
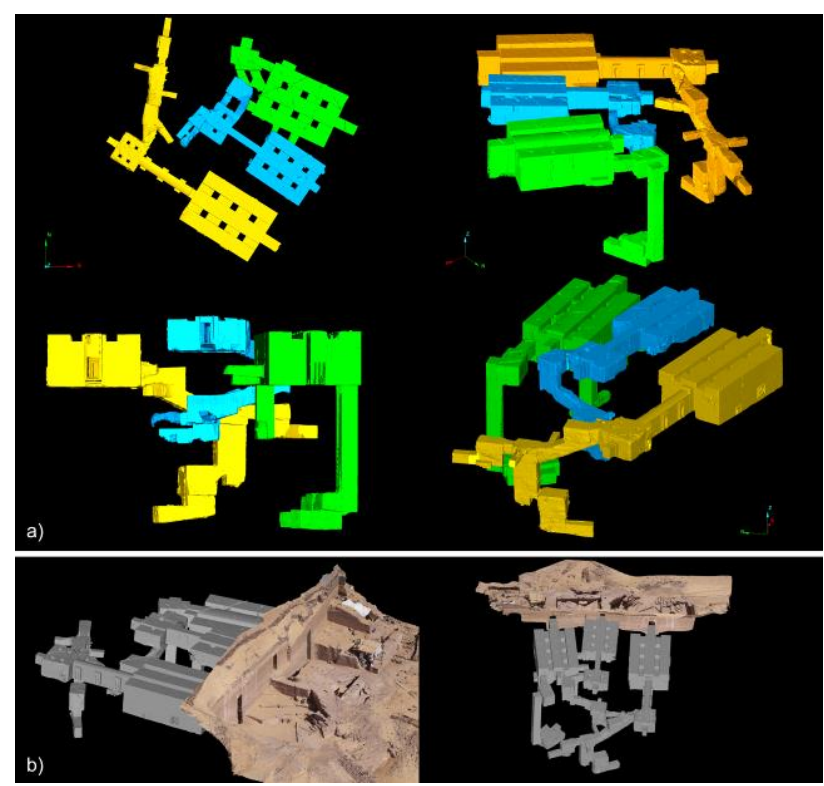

Figure 7. a) Views of the 3D models obtained: QH31 in yellow, QH32 in blue and QH33 in green; b) views of the 3D models of the tombs with the exterior model

Other secondary results can be obtained from the method applied. One to be highlighted is that related to the orientation process based on the estimation of the coordinates of the targets using the TLS. The results of the comparison between the coordinates of the sets of Targets B (total station) and Targets
B' (TLS) have shown low discrepancies, with RMS values of about 0.001, 0.009 and $0.007 \mathrm{~m}(\mathrm{QH} 31, \mathrm{QH} 32$ and QH33).

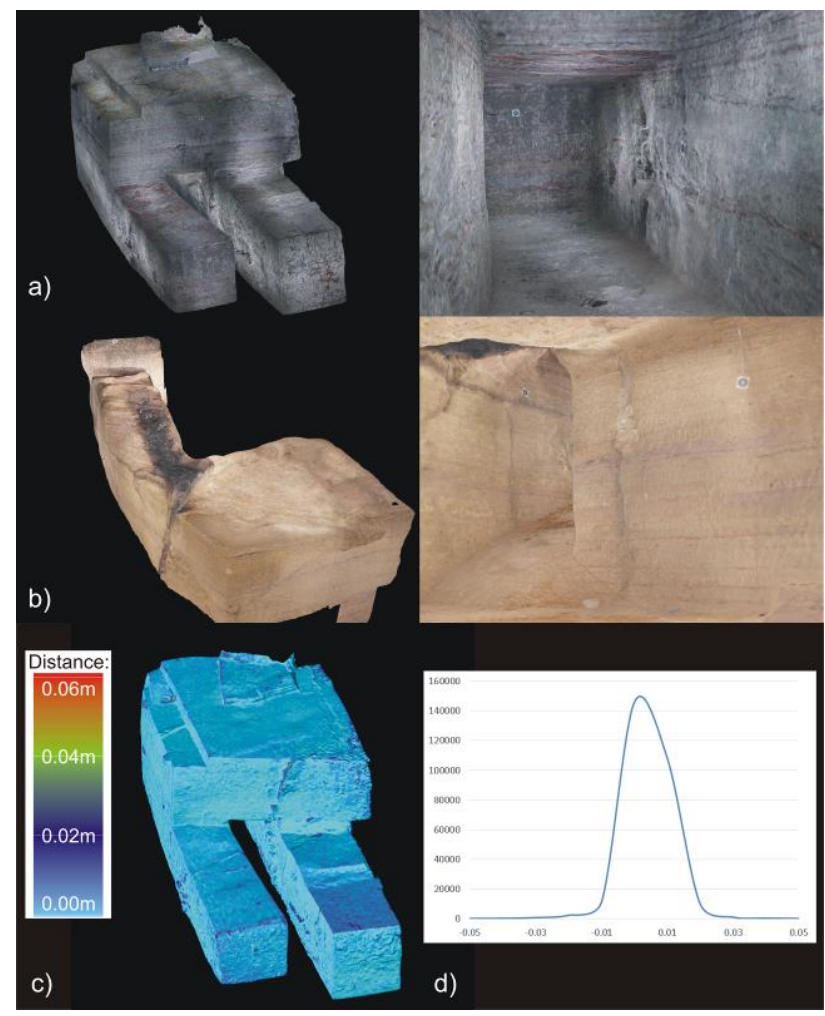

Figure 8. a) Views of the CRP model of the QH33 burial chamber; b) Views of the CRP model of the QH32 intermediate chamber; c) distance between the CRP model and the TLS model of the QH33 burial chamber; d) histogram of distances between the CRP and the TLS model (Qh33 burial chamber)

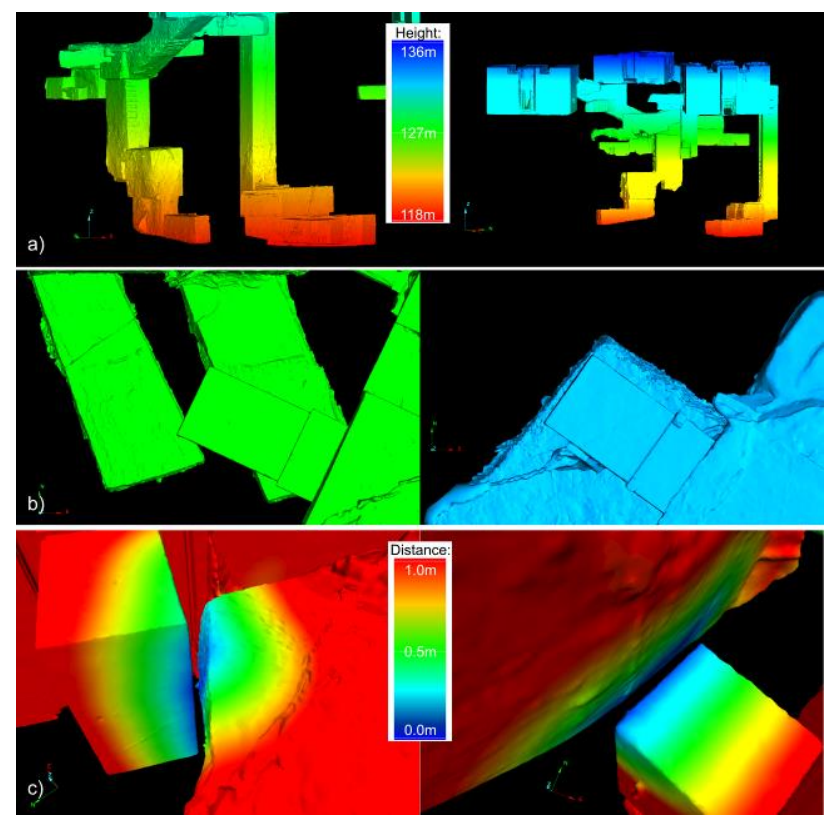

Figure 9. Views of the 3D models obtained: a) Similar height of the QH31 and the QH33 burial chambers; b) planimetric coincidence of the sanctuaries with the burial chambers $(\mathrm{QH} 32$ and $\mathrm{QH} 33$ ); c) examples of reduced distance between the $\mathrm{QH} 32$ and the QH33 tombs. 
Information extracted from the 3D models has helped architects and archaeologists to contrast their premises about the spatial behaviour of these tombs. As examples we have the coincidence of heights of the deepest burial chambers of the QH31 and QH33 tombs (Figure 9a), the planimetric coincidence of the sanctuary (Figure $9 \mathrm{~b}$ ) with the burial chamber located 9 and 13 $\mathrm{m}$ below in the $\mathrm{QH} 32$ and $\mathrm{QH} 33$ cases, the reduced distance between the QH32 and the QH33 tombs (Figure 9c), etc. We highlight that this separation is about $10 \mathrm{~cm}$ at the closest points. It supposes an incredible value and the fact that these tombs were not intersected considering the tools and methods developed in the epoch when these tombs were excavated is remarkable.

In addition, the 3D models have also shown two main directions of the rock fractures, which are coincident with external geological features. Thanks to these models, we can confirm that these fractures were used to facilitate the excavation work. The models of certain elements of interest, such as the burial chambers, were obtained using photogrammetry

\section{CONCLUSIONS}

The results of this study have allowed the obtaining of the first 3D documentation of three of the main tombs of the Necropolis of Qubbet el Hawa in Aswan (Egypt). All of this documentation falls under the same reference system, allowing them to be studied in their entirety, along with the rest of the elements of the Necropolis. This information is very important for documentation purposes but also to understand the spatial behaviour of these structures and the excavation processes developed by ancient Egyptians 4000 years ago.

The method applied in this study has demonstrated its efficiency in data capturing. This aspect is very important when these works coincide with other archaeological works. More concretely, the method takes advantage of the fast, high density and accurate measurements given by TLS jointly to the fast photograph registration of those elements of interest. The reduction of the number of targets estimated with total station, thanks to the use of TLS to estimate the coordinates, has increased the efficiency of the field work considerably. In addition, the method has also shown a high level of efficiency in narrow spaces and poor illumination conditions. The use of TLS as a basic source of data has allowed us to generate a complete model of the tombs because of its feasibility in acquiring images in reduced spaces and the independence of the illumination conditions. Regarding the space, the sole limitation is the size of the scanner. In addition, TLS has also demonstrated its efficiency in the registration of vertical shafts (up to $13 \mathrm{~m}$ ).

Future studies will focus on improvement of the photographic acquisition in order to reduce the field time, thus increasing the efficiency of the method and the number of elements modelled using photogrammetry (e.g. vertical shafts).

\section{ACKNOWLEDGEMENTS}

The present paper is the result of research carried out with funds provided by the MINECO (Government of Spain), as part of the project HAR2016-75533-P "Excavación, estudio histórico y conservación de las tumbas del Reino Medio de la necrópolis de Qubbet el Hawa (Asuán, Egipto)", as well as private institutions such as Fundación Gaselec, Fundación Palarq, Asociación Española de Egiptología and Cátedra de Egiptología de la Universidad de Jaén.

\section{REFERENCES}

Ahmon, J. 2004. The Application Of Short-Range 3d Laser Scanning For Archaeological Replica Production: The Egyptian Tomb Of Seti I. Photogramm. Rec., 19(106), 111-127.

Angelini, A., Vittozzi, G.C., Baldi, M., 2016. The high official Harkhuf and the inscriptions of his tomb in Aswan (Egypt). An integrated methodological approach. ACTA IMEKO, 5(2), 7179.

Barazzetti, L., Previtali, M., Roncoroni, F., 2017a. 3D Modelling with the Samsung Gear 360. Int. Arch. Photogramm. Remote Sens. Spatial Inf. Sci., XLII-2-W3, 85-90.

Barazzetti, L., Previtali, M., Roncoroni, F., 2017b. Fisheye lenses for 3D modeling: evaluations and considerations. Int. Arch. Photogramm. Remote Sens. Spatial Inf. Sci., XLII-2/W3, 79-84.

Blockley, P., Morandi, S., 2015. The recording of two late Roman towers, Archaeological Museum, Milan 3D documentation and study using image-based modelling. In Digital Heritage 2015, IEEE, Granada, Spain, 103-106.

Brutto, M.L., Meli, P., 2012. Computer vision tools for 3D modelling in archaeology. International Journal of Heritage in the Digital Era, 1, 1-6.

Campana, S., 2017. Drones in Archaeology. State-of-the-art and Future Perspectives. Archaeol. Prospect., 24(4), 275-296.

Cardenal, J., Mata, E., Castro, P., Delgado, J., Hernandez, M.A., Pérez, J.L., Ramos, M., Torres, M., 2004. Evaluation of a digital non metric camera (Canon D30) for the photogrammetric recording of historical buildings. Int. Arch. Photogramm. Remote Sens. Spatial Inf. Sci., XXXV-B5, 564-569.

Celikoyan, T.M., Altan, M.O., Kemper, G., Toz, G., 2003. Calibrating and using an olympus camera for balloon photogrammetry. In Proc. XIXth International Syposium-CIPA 2003, Antalya, Turkey, 380-382.

Chandler, J.H., Fryer, J.G., Jack, A., 2005. Metric capabilities of low-cost digital cameras for close range surface measurement. Photogramm. Rec., 20(109), 12-26.

Colomina, I., Molina, P., 2014. Unmanned aerial systems for photogrammetry and remote sensing: A review ISPRS $J$. Photogramm., 92, 79-97.

Covas, J., Ferreira, V., Mateus, L., 2015. 3D reconstruction with fisheye images strategies to survey complex heritage buildings. In Digital Heritage 2015., IEEE, Granada, Spain, 123-126.

Echeverría, E., Celis, F., Morales, A., da Casa, F., 2019. The Tomb of Ipi: 3D Documentation in a Middle Kingdom Theban Necropolis (Egypt, 2000 BCE). Int. Arch. Photogramm. Remote Sens. Spatial Inf. Sci., XLII-2/W9, 319-324.

Fernández-Palacios, B.J., Rizzi, A., Remondino, F., 2013. Etruscans in 3D-Surveying and 3D modeling for a better access and understanding of heritage. Virtual archaeol. rev., 4(8), 8589. 
Fiorillo, F., Limongiello, M., Fernández-Palacios, B.J., 2016. Testing GoPro for 3D model reconstruction in narrow spaces. Acta IMEKO, 5(2), 64-70.

Furukawa, Y., Hernández, C., 2015. Multi-view stereo: A tutorial. Foundations and Trends® in Computer Graphics and Vision, 9(1-2), 1-148.

Georgopoulos, A., Karras, G.E., Makris, G.N., 1999. The photogrammetric survey of a prehistoric site undergoing removal. Photogramm. Rec., 16(93), 443-456.

Green, S., Bevan, A., Shapland, M., 2014. A comparative assessment of structure from motion methods for archaeological research. J. Archaeol. Sci., 46, 173-181.

Guarnieri, A., Remondino, F., Vettore, A., 2006. Digital photogrammetry and TLS data fusion applied to Cultural Heritage 3D modeling. Int. Arch. Photogramm. Remote Sens. Spatial Inf. Sci., XXXVI-5.

Habachi, L., 1985. Elephantine IV. The Sanctuary of Heqaib. 2 vols. Mainz am Rhein, Philip von Zabern.

Jiménez-Serrano, A., García-González, L., 2017. Los complejos funerarios de los gobernadores de elefantina durante la Dinastía XII en Qubbet el-Hawa (Asuán): Una evolución tipológica de carácter local. In Egiptología Ibérica 2017. Estudios y nuevas perspectivas, Ediciones de la Universidad de Castilla La Mancha, Cuenca, Spain, 111-138.

Jiménez-Serrano, A., Sánchez-León, J. C., 2019. Le Premier Nome du sud de l'Égypte au Moyen Empire, BAR International Series, Oxford.

Koenderink, J.J., Van Doorn, A.J., 1991. Affine structure from motion. J Opt. Soc. Am. A, 8(2), 377-385.

Lerma, J.L., Navarro, S., Cabrelles, M., Villaverde, V., 2010. Terrestrial laser scanning and close range photogrammetry for 3D archaeological documentation: the Upper Palaeolithic Cave of Parpalló as a case study. J. Archaeol. Sci., 37 (3), 499-507.

Lima de, R., Vergauwen, M., 2018. From TLS Recoding to VR Environment for Documentation of the Governor's Tombs in Dayr al-Barsha, Egypt. In 2018 IEEE International Symposium on Mixed and Augmented Reality Adjunct (ISMAR-Adjunct), IEEE, Munich, Germany, 293-298

Lowe, D.G., 2004. Distinctive image features from scaleinvariant keypoints. Int. J. Comput. Vision, 60(2), 91-110.

Martínez, S., Ortiz, J., Gil, M.L., Rego, M.T., 2013. Recording complex structures using close range photogrammetry: The cathedral of Santiago de Compostela. Photogramm. Rec., 28(144), 375-395.

Martínez, S., Ortiz, J., Gil, M., 2015. Geometric documentation of historical pavements using automated digital photogrammetry and high-density reconstruction algorithms. $J$. Archaeol. Sci., 53, 1-11.

Martínez-Hermoso, J.A., Martínez-Hermoso, F., Montes-Tubío, F.D.P., Jiménez-Serrano, A.J., 2015. Geometry and Proportions in the Funeral Chapel of Sarenput II. Nexus Netw. J., 17(1), 287-309.

Martínez-Hermoso, J.A., Mellado-García, I., Martínez de Dios, J.L, Martínez-Hermoso, F., Espejo-Jiménez, A.M., JiménezSerrano, A., 2018. The construction of tomb group QH31 (Sarenput II) through QH33. Part I: The exterior of the funerary complexes, The Journal of Ancient Egyptian Architecture, 3, $25-44$.

McCarthy, J., 2014. Multi-image photogrammetry as a practical tool for cultural heritage survey and community engagement. $J$. Archaeol. Sci., 43, 175-185.

Mozas-Calvache, A.T., Pérez-García, J.L., Cardernal-Escarcena, F.J., Delgado, J., Mata de Castro, E., 2012b. Comparison of Low Altitude Photogrammetric Methods for Obtaining Dems and Orthoimages of Archaeological Sites. Int. Arch. Photogramm. Remote Sens. Spatial Inf. Sci., XXXIX-B5, 577581.

Nabil, M., Betrò, M., Metwallya, M.N., 2013. 3D reconstruction of ancient Egyptian rockcut tombs: the case of Midan 05. Int. Arch. Photogramm. Remote Sens. Spatial Inf. Sci., XL-5/W2, 443-447.

Nex, F., Remondino, F., 2014. UAV for 3D mapping applications: a review. Appl. Geomatics, 6(1), 1-15.

Ogleby, C.L., Papadaki, H., Robson, S., Shortis, M.R., 1999. Comparative camera calibrations of some "off the shelf" digital cameras suited to archaeological purposes. Int. Arch. Photogramm. Remote Sens. Spatial Inf. Sci., XXXII-5/W11, 69-75.

Ortiz, J., Gil, M.L., Martínez, S., Rego, T., Meijide, G., 2013. Three-dimensional Modelling of Archaeological Sites Using Close-range Automatic Correlation Photogrammetry and Low-altitude Imagery. Archaeol. Prospect., 20(3), 205-217.

Pérez-García, J.L., Mozas-Calvache, A.T., Gómez-López, J.M., Jiménez-Serrano, A., 2018. Three-dimensional modelling of large archaeological sites using images obtained from masts. Application to Qubbet el-Hawa site (Aswan, Egypt). Archaeol. Prospect. https://doi.org/10.1002/arp.1728

Perfetti, L., Polari, C., Fassi, F., 2017. Fisheye photogrammetry: tests and methodologies for the survey of narrow spaces. Int Arch. Photogramm. Remote Sens. Spatial Inf. Sci., XLII-2/W3, 573-580.

Rothermel, M., Wenzel, K., Fritsch, D., Haala, N., 2012. SURE: Photogrammetric surface reconstruction from imagery. In Proceedings LC3D Workshop, Berlin, Germany.

Scharstein, D., Szeliski, R., 2002. A taxonomy and evaluation of dense two-frame stereo correspondence algorithms. Int. J. Comput. Vision, 47(1-3), 7-42.

Seitz, S.M., Curless, B., Diebel, J., Scharstein, D., Szeliski, R., 2006. A comparison and evaluation of multi-view stereo reconstruction algorithms. In IEEE Computer Society Conference on Computer Vision and Pattern Recognition, IEEE, New York, USA, 519-528. 
Szeliski, R., 2011. Computer Vision: Algorithms and Applications. Springer, London.

Ullman, S., 1979. The interpretation of structure from motion. Proc. Royal Soc. London B, 203, 405-426.

Waldhäusl, P., Ogleby, C.L., 1994. 3 x 3 rules for simple photogrammetric documentation of architecture. Int. Arch. Photogramm. Remote Sens., 30, 426-429.

Waldhäusl, P., Ogleby, C.L., Lerma, J.L., Georgopoulos, A., 2013. 3 x 3 rules for simple photogrammetric documentation of architecture. http://cipa.icomos.org/wpcontent/uploads/2017/02/CIPA_3x3_rules_20131018.pdf

Westoby, M.J., Brasington, J., Glasser, N.F., Hambrey, M.J., Reynolds, J.M., 2012. 'Structure-from-Motion' photogrammetry: A low-cost, effective tool for geoscience applications. Geomorphology, 179, 300-314. 